\author{
Military Technical College \\ Kobry El-Kobbah, \\ Cairo, Egypt.
}

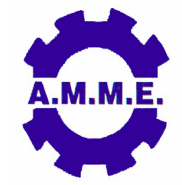

$15^{\text {th }}$ International Conference on Applied Mechanics and Mechanical Engineering.

\title{
RECYCLING OF ALUMINUM ALLOY WITH DIMOX AND RHEOCASTING FUNCTIONALIZE HIGH PERFORMANCE STRUCTURAL FOAM COMPOSITE
}

\author{
B. M. Rabeeh *
}

\begin{abstract}
Great efforts are aimed towards the synthesis and the development of structural composite materials. Direct metal oxidation, DIMOX introduced for hybrid composite processing. However, oxidation temperatures around $1100^{\circ} \mathrm{C}$ lead to the formation of porous ceramic materials. To utilize this porosity intentionally for foam production, a new approach based on synergetic effect of alloying elements, DIMOX and semisolid (rheocsting) processing is developed. A semisolid reaction, rheocasting is introduced to control porosity shape and size. Aluminum alloy 6xxx (automobile scrap pistons) is recycled for this objective and DIMOX at $1100^{\circ} \mathrm{C}$ for $30 \mathrm{~min}$, then rheocasting, at $750^{\circ} \mathrm{C}$ for 30 minutes. The effect of $\alpha$-Fe powder, $\mathrm{Mg}$ powder, and Boric acid powder established for the objective of a hybrid structural metal matrix composite in bulk foam matrix. The kinetic of formation of hybrid metal matrix foam composite is introduced. Microstructural and mechanical characterization established for high performance Aluminum foam hybrid composite materials.
\end{abstract}

\section{KEY WORDS}

Recycle, DIMOX, Rheocasting, hybrid, composite, Boric acid, Al-foam.

\footnotetext{
* Professor, Dept. of Engineering and Materials Sci., German Univ. in Cairo, Egypt.
} 


\title{
NOMENCLATURES
}

\author{
DIMOX Direct Metal Oxidation. \\ EDS Energy Dispersive X-Ray Spectroscopy. \\ SEM Scanning Electron Microscopy.
}

\section{INTRODUCTION}

Aluminum scrap 6xxx alloy (automobile scrap parts) is recycled utilizing DIMOX for the objective of minimizing cost and maximizing performance. DIMOX is applied at three levels of temperatures, $950^{\circ} \mathrm{C}, 1000^{\circ} \mathrm{C}$, and $1050^{\circ} \mathrm{C}, 1100^{\circ} \mathrm{C}$ for different holding time then cast in a metallic mold [1]. No clear evidence of oxidation before $920^{\circ} \mathrm{C}$, while porosity is dominant around $1100^{\circ} \mathrm{C}$ [1-2]. However, oxidation temperatures at $1100^{\circ} \mathrm{C}$ lead to the formation of porous ceramic materials, this porosity is intentionally added and recommended for metallic foam production. A semisolid reaction, rheocasting is introduced to control porosity shape and size. A new approach based on the synergetic effect of alloying elements, DIMOX and semisolid (rheocsting) processing is introduced.

Three sets of samples are prepared to characterize the effect of DIMOX and rheocasting on material attributes. The first set of samples DIMOX at $1100^{\circ} \mathrm{C}$ for 20 minutes holding time and poured in a metallic mold. The second set of samples is prepared with semisolid work rheocasting followed direct metal oxidation. Rheocasting is applied at $750^{\circ} \mathrm{C}$ for 20 minutes. The third set of samples is introduced for characterizing the effect of addition of the alloying elements. Alloying element effect on DIMOX and rheocasting is also investigated by applying $5 \%$ of $\mathrm{Si}$, $\alpha-\mathrm{Fe}, \mathrm{Mg}$ powder and boric acid powder separately. The commencement of $\square-$ alumina, intermetallic fibers/whiskers, and the segregation, of alloying elements is introduced in a residual bulk aluminum matrix [1-5].

The kinetic of DIMOX with the synergetic effects and the segregation of alloying elements induced delocalized zone of interests. Both composite constituents are controlled for the objective of obtaining metal matrix composite reinforced with either ceramic phase alumina or intermetallic whiskers/fibers. At certain level of parametric study, delocalized zone of interest induced functionally-gradient-materials, FGM. Porosity is also delocalized and controlled through semisolid reaction at $750^{\circ} \mathrm{C}$ in crucible for 20 minutes.

The effect of $\alpha-\mathrm{Fe} \mathrm{Mg}$, as well as boric acid powder addition resolved with different functions. Addition of $\alpha$-Fe powder has a powerful effect of nucleating intermetallic fibers as well as alumina fibers homogeneously distributed along residual porous aluminum. Synergetic effects of $\alpha-F e$ with DIMOX as well as rheocasting have a dominant effect on the morphology of composite constituents. Addition of $\alpha-\mathrm{Fe}$ introduced a new hybrid material; aluminum alloy reinforced with ceramic alumina as well as intermetallic fibers, in residual porous aluminum is also introduced. Nucleation and growth of reinforcement has an implicit effect of alloying element segregation in bulk aluminum [6]. Different delocalized zone of microstructures resolve bulk aluminum and porous aluminum matrix [7-8]. Magnesium addition has a 
new functional hybrid material. Ceramic alumina whiskers, instead of fibers with less percentage of intermetallic fibers are introduced. Boric acid addition is also introduced for fibrous aluminum borate in a metallic porous material that controlled via rheocasting to aluminum foam materials.

A clear porosity obtained with DIMOX is now being controlled in shape and size for better mechanical properties as well as a new emerging process for producing aluminum foam. The addition of alloying elements with both DIMOX and rheocasting process induced different morphology of ceramic reinforcement with intermetallic whiskers in a residual aluminum metal matrix composite. Alloying element segregation has its synergetic effect for introducing new composite foam material. The control of porosity as well as the control of reinforcement established for the assessment of high performance aluminum foam with intermetallic whiskers and fibers.

Scanning electron microscopy and energy dispersive X-ray spectroscopy (EDS) is utilized. In addition, mechanical characterization is introduced through 3-point test. Modulus of rupture is calculated for square cross section sample and compared. The control of porosity is established by semisolid rheocasting process which tends to reduce internal stress raisers of flake porosity to a controlled shape and size. Mechanical characterization is also introduced through 3-point testing of metallic mold casted samples of $10 \times 10 \times 55 \mathrm{~mm}$. Modulus of rupture [MOR] is calculated for different samples through DIMOX process and/or DIMOX followed by rheocasting. Rheocasting has a clear evidence of controlling porosity shape and size that realized in increasing flexural strength.

\section{EXPERIMENTAL RESULTS AND DISCUSSION}

Figure 1 presents Porous structure of recycled aluminum alloy DIMOX at $1100^{\circ} \mathrm{C}$ for 20 minutes. Porosity is clearer and visible at $1100^{\circ} \mathrm{C}$ is now being controlled in shape, size and distribution through addition of alloying elements as well as utilizing semisolid rheocasting at $750^{\circ} \mathrm{C}$ for 20 minutes. Addition of $\alpha-F e$ introduced with intermetallic fibers as well as delocalized whiskers of alumina in a porous aluminum matrix and presented in Figure 2. The application of Rheocasting and semisolid reaction at $750^{\circ} \mathrm{C}$ followed DIMOX of Al alloy recycled and DIMOX with $\alpha$-Fe addition has the effect of redistribution of porosity shape and size [Figure 3].

The addition of $\alpha$-Fe induces the formation of intermetallic fibers with dendritic growth of residual aluminum [Fig. 2]. More evidence of intermetallic formation within alumina phase is also introduced in Figure 4 for recycled Al that DIMOX at $1100^{\circ} \mathrm{C}$ for 20 min. with the addition of $\mathrm{Mg}$ powder. The segregation of alloying elements along with delocalized zone of interests introduced for recycled aluminum DIMOX at $1100^{\circ} \mathrm{C}$ for 20 minutes induced by the addition of Mg powder [Fig. 4]. Porous matrix along with alumina whiskers established via DIMOX. Rheocasting induce control porosity shape and size as will as delocalized distributed porosity [Fig. 5]. Porosity shape and size is controlled via rheocasting and presented in Figure 6.

The addition of boric acid is established in the DIMOX of recycled Al-alloy at $1100^{\circ} \mathrm{C}$ 
for 20 minutes and presented in Figure 7. Semisolid rheocasting established at $750^{\circ} \mathrm{C}$ for 20 minutes and presented in Figure 6. Aluminum borate, alumina and intermetallic whiskers as reinforcement established in metallic foam matrix and presented in Figure 8.

In addition to resolve the kinetic of DIMOX along with alloying elements effects, semisolid rheocasting interaction is also introduced. Porosity more dominated by $\alpha$ $\mathrm{Fe}$ and $\mathrm{Mg}$ addition. The addition of boric acid is also established with porosity. This work focused on resolving the effect of $\alpha-\mathrm{Fe}, \mathrm{Mg}$ and boric acid addition to recycled Al-alloy that DIMOX at $1100^{\circ} \mathrm{C}$ and 20 minute holding time. In addition, resolving the kinetic of rheocasting on these set of samples DIMOX at $1100^{\circ} \mathrm{C}$ for $20 \mathrm{~min}$. then followed by rheocasting at $750^{\circ} \mathrm{C}$ for 20 minutes. New nontraditional method established for hybrid composite processing in metallic aluminum foam. Figure 9 presents aluminum foam matrix of recycled aluminum alloy at $1100^{\circ} \mathrm{C}$ for 20 minutes and rheocasting at $750{ }^{\circ} \mathrm{C}$ for 29 minutes with boric acid addition. Figures 10 to 13 present EDX of alumina, intermetallic and residual aluminum through $\mathrm{Mg}$ alloy addition and boric acid respectively. Mechanical characterization introduced via 3point test and modulus of rupture and presented in Table 1.

The addition of both $\alpha$-Fe and $\mathrm{Mg}$ induced a clear evidence of alumina phase at DIMOX temperatures in a porous matrix. However a clear difference introduced that resolve intermetallic fibers via boric acid addition. In addition the effect of rheocasting introduced with the control of porosity shape and size. Kinetic of DIMOX reaction as well as semisolid reaction introduced with the segregation of alloying elements along with intermetallic and residual Aluminum matrix. Semisolid reaction not only introduced for the control of foam formation but also for mechanical characterization and the enhancement of materials properties. The formation of new phase in residual aluminum due to the addition of both $\alpha-\mathrm{Fe}, \mathrm{Mg}$ and boric acid induced an increase of MOR [Table 1].

\section{CONCLUSIONS}

The effect of addition $\alpha$-Fe powder, Mg powder as well as boric acid resolved with different functions. Addition of $\alpha$-Fe powder has a powerful effect of nucleating intermetallic fibers as well as alumina fibers homogeneously distributed along residual aluminum. Synergetic effects of $\alpha$-Fe with DIMOX as well as rheocasting have a dominant effect on the morphology of composite constituents. Clear intermetallic fibers as well as alumina fibers are introduced at $1100^{\circ} \mathrm{C}$ with scanning electron microscopy. However, the addition of $\alpha$-Fe introduced a new functional hybrid material, aluminum alloy reinforced with ceramic alumina as well as intermetallic fibers, in residual porous aluminum. The control of porosity is dominated by rheocasting process which tends to reduce stress raisers of flake porosity to a controlled shape and size. Magnesium addition has another new functional hybrid material. Ceramic alumina whiskers, instead of fibers with less percentage of intermetallic fibers are introduced. The clear porosity obtained with DIMOX is now being controlled in shape and size for better mechanical properties as well as a new emerging process for producing not aluminum foam but also hybrid aluminum foam reinforced with ceramic alumina or intermetallic fibers. 
Boric acid has a dominant effect of introducing aluminum borate along with homogeneous foam matrix. Nontraditional method for hybrid aluminum foam is now being introduced via DIMOX and rheocasting. The addition of alloying elements with the nontraditional processes [DIMOX and rheocasting] clearly dominates multifunctional materials. The first established with $\alpha$-Fe addition leading to the third generation metal matrix composite with both alumina and intermetallic fibers reinforcements. The second dominated by the addition of $\mathrm{Mg}$ that induced whiskers with new foaming matrix materials. The third introduce with boric acid that induce aluminum borate in aluminum foam matrix. This may lead to more mechanical properties as well as high performance materials. The addition of semisolid process after DIMOX has a clear enhancement not only at micro-structural evidence, but also at mechanical characterization. There is some evidence of mechanical enhancement as increase of modulus of rupture for different samples. Synergetic effects of alloying elements as well as DIMOX parametric induced different intermetallic kinetics as well as delocalized zone of interests. DIMOX processing induced engineering of new materials with different functions.

\section{REFERENCES}

[1] B. M. Rabeeh, A.M. Elmahallawy, S. H. Haddad, and M. A. Ibrahim "Development and Processing of a functionally Gradient Ceramic/Metal Materials ", Proceeding of the 9th Applied Mechanics and Mechanical Engineering Conference, AMME Conf. 16-18 May, 2000, Cairo, Egypt.

[2] C.D. Marinara, S.J. Andersen, J. Jansen, H.W. Zandbergen, The influence of temperature and storage time at RT on nucleation of the $\alpha$-phase in a $6082 \mathrm{Al}-$ Mg-Si alloy, Acta Mater. 51 (2003) 789-796.

[3] N.C.W. Kuijpers, W.H. Kool, P.T.G. Koenis, K.E. Nilsen, I.Todd, and S. van der Zwaag, "Assessment of different techniques for quantification of $\alpha$-Al (FeMn) Si and $\beta$-AlFeSi intermetallics in AA 6xxx alloys", Materials Characterization 49 (2003) 409-420.

[4] M. Warmuzek, J. Sieniawski, K. Wicher, and G. Mrówka- Nowotnik, "The study of distribution of the transition metals and Si during primary precipitation of the intermetallic phases in Al-Mn-Si alloys", Journal of Materials Processing Technology 175 1-3 (2006) 421-426.

[5] L.A. Dobrzanski, W. Borek, and R. Maniara, "Influence of the crystallization condition on Al-Si-Cu casting alloys structure", Journal of Achievements in Materials and Manufacturing Engineering 18, 1-2 (2006).

[6] G. Mrówka-Nowotnik, J. Sieniawski, and M. Wierzbińska, "Analysis of intermetallic particles in alsi1mgmn aluminium alloy", Journal of of Achievements in Materials and Manufacturing Engineering, Volume 20, issues 1-2, january-february 2007.155-158.

[7] B. M. Rabeeh, "Engineering Of Hybrid Composite/ Intermetallic Al-Fe-Si Fibers For Structural Materials Applications", Proceeding of the 14th Applied Mechanics and Mechanical Engineering Conference, AMME Conf. 25-27 May, 2010, Cairo, Egypt.

[8] B. M. Rabeeh, "Alloying Elements and DIMOX Induced High Performance Structural Foam Composite ", Proceeding of 2011 International Conference on Advanced Materials Engineering ICAME 2011, Conf. 1-3October, 2011, Cairo, Egypt. 


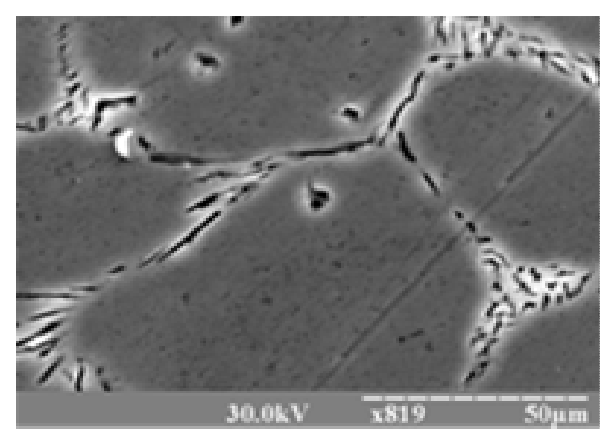

Fig. 1. Porous structure DIMOX at $1100^{\circ} \mathrm{C}$ for 20 minutes.

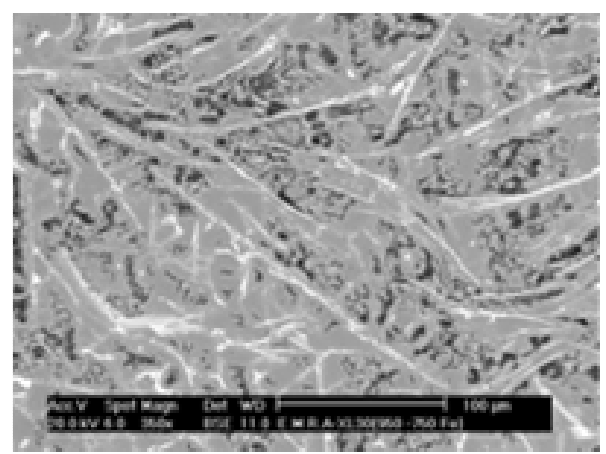

Fig. 2. $\alpha$-Fe induced intermetallic fibers with porous matrix [DIMOX at $1100^{\circ} \mathrm{C}$. $20 \mathrm{~min}$ ].

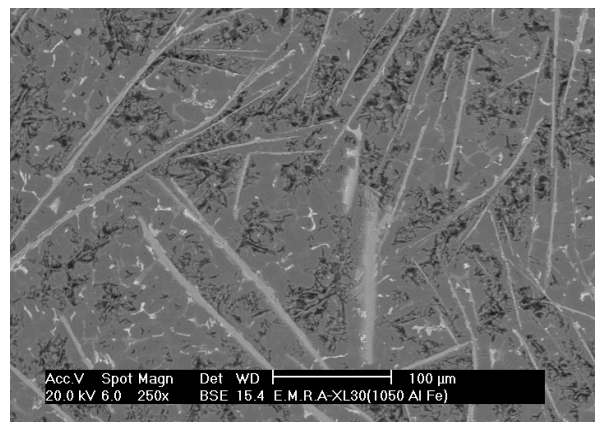

Fig.3. $\alpha$-Fe induced intermetallic fibers in delocalized bulk and foam matrix [DIMOX at $1100^{\circ} \mathrm{C}$. $20 \mathrm{~min}$. and rheocasting at $750^{\circ} \mathrm{C}$ for $20 \mathrm{~min}$.].

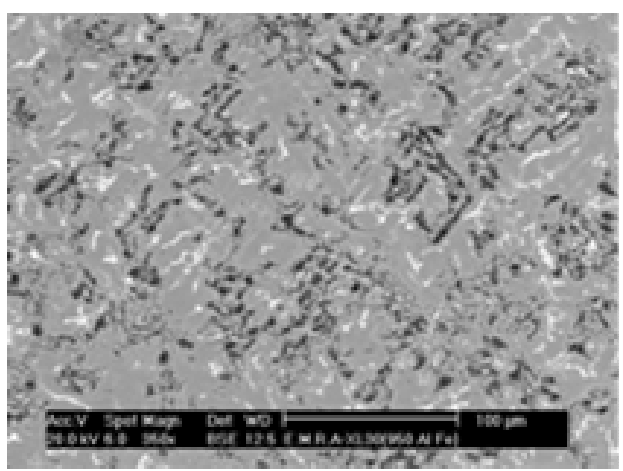

Fig. 4. $\mathrm{Mg}$ induced intermetallic whiskers in porous Aluminum [DIMOX at $1100^{\circ} \mathrm{C} .20 \mathrm{~min}$ ]. 


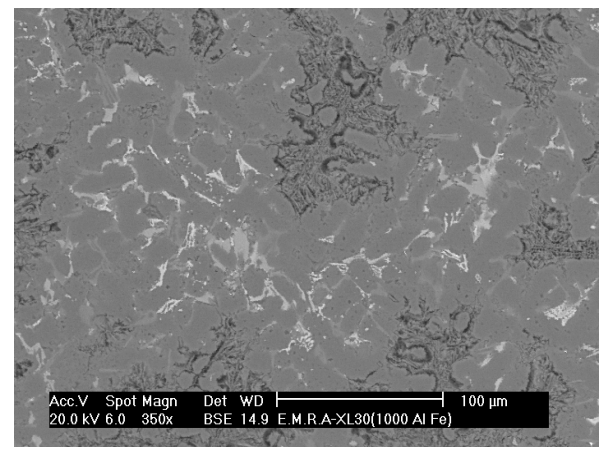

Fig. 5. Mg induced intermetallic whiskers in delocalized bulk and foam matrix [DIMOX at $1100^{\circ} \mathrm{C} .20$ min. and rheocasting at $750^{\circ} \mathrm{C}$ for $20 \mathrm{~min}$.].

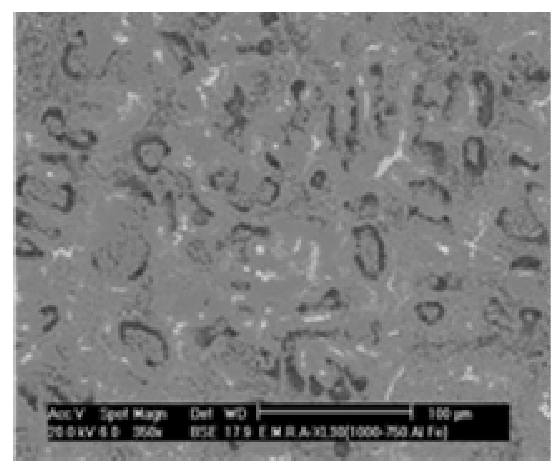

Fig. 6. Rheocasting control shape and size of porous Aluminum.

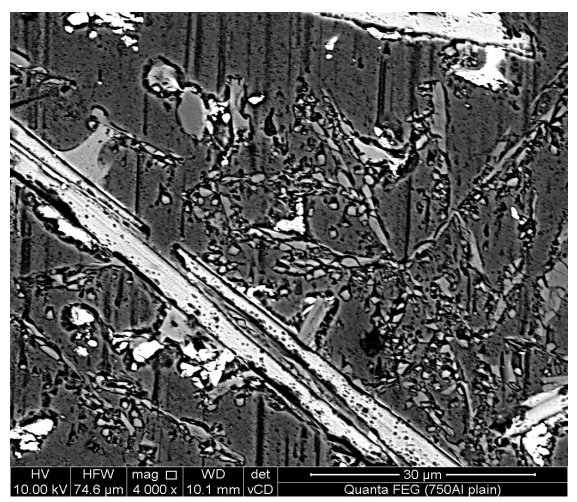

Fig. 7. Boric acid induced intermetallic whiskers with Al borate in delocalized bulk porous matrix [DIMOX at $1100^{\circ} \mathrm{C} .20 \mathrm{~min}$.]

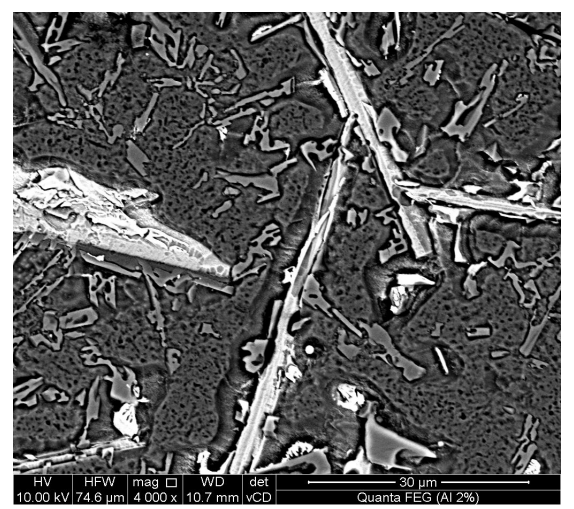

Fig. 8. Boric acid induced Al borate in delocalized bulk and foam matrix [DIMOX at $1100^{\circ} \mathrm{C} .20 \mathrm{~min}$. and rheocasting at $750^{\circ} \mathrm{C}$ for $20 \mathrm{~min}$. 


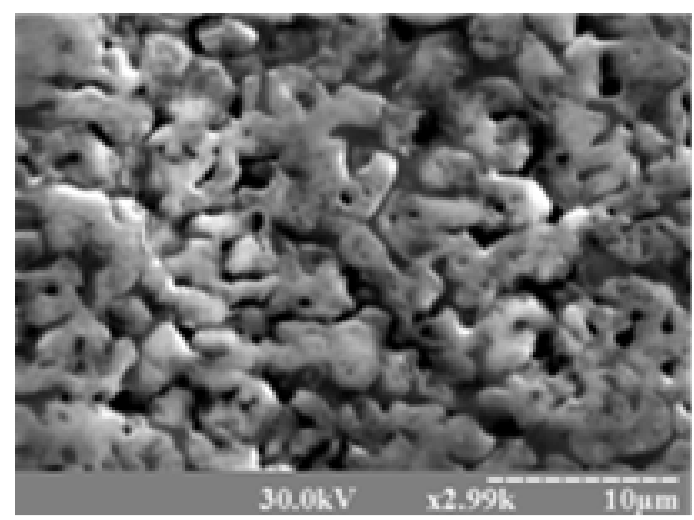

Fig. 9. Aluminum foam with uniformly distributed porosity [DIMOX + Rheocasting].

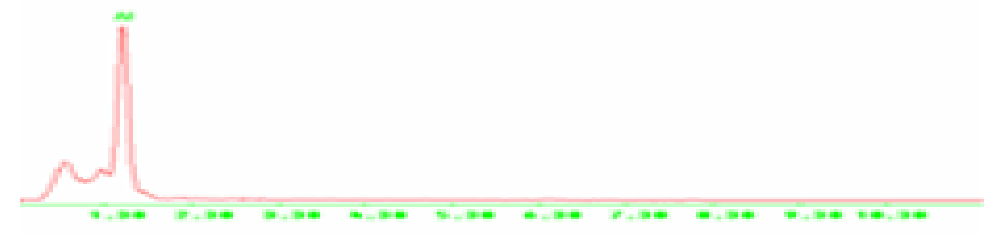

Fig. 10: EDS resolve alumina [gray spot].

Label A: Sample 950 Al Fe[Spot White]

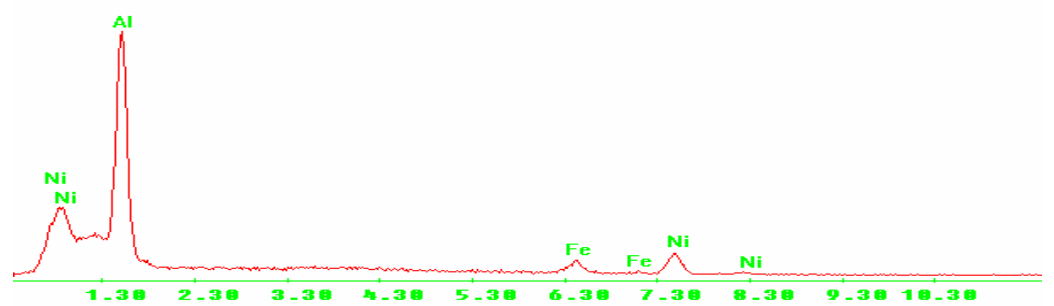

Fig.11. EDS resolve intermetallic fibers [white spot].

Label A: Sample $1050-750$ Fe[Spot Gery]

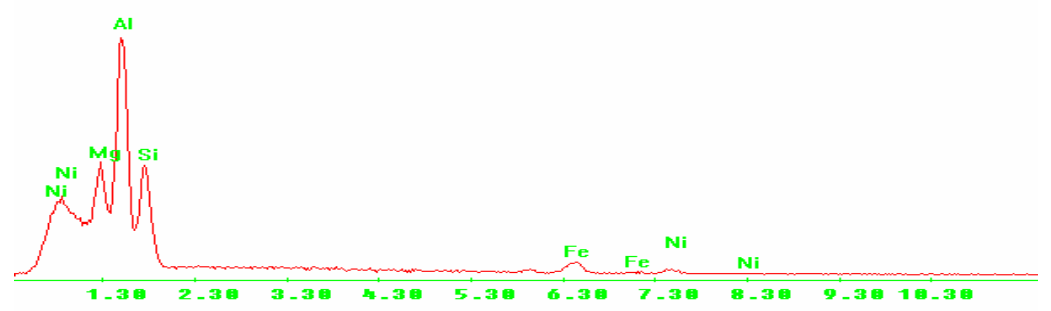

Fig.12. EDS resolve residual aluminum [white spot]. 


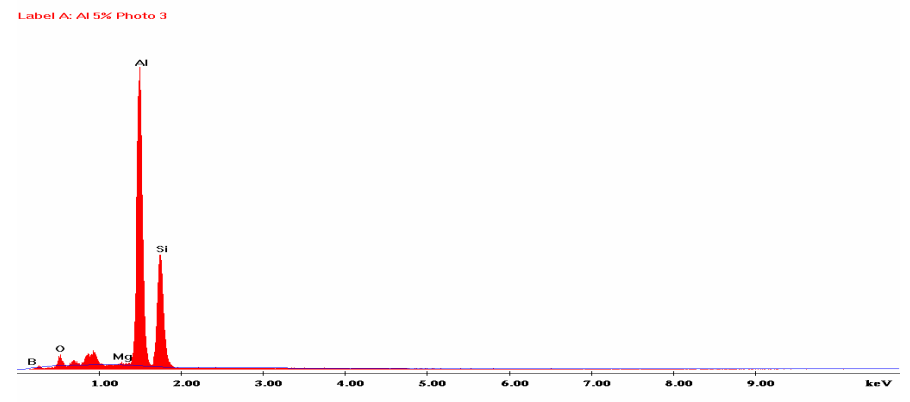

Fig.13. EDS resolve Aluminum borate via boric acid addition [white spot].

Table 1: Modulus of Rupture resolves the effect of DIMOX and Rheocasting samples.

\begin{tabular}{|c|c|c|c|c|c|c|}
\hline & \multicolumn{3}{|c|}{ DIMOX } & \multicolumn{3}{|c|}{ Rheocasting } \\
\hline lassification & $\begin{array}{l}\text { Force } \\
{[\mathrm{N}]}\end{array}$ & $\begin{array}{l}\text { Jeflection } \\
\text { [mm] }\end{array}$ & $\begin{array}{l}\text { MOR } \\
\text { [MPa] }\end{array}$ & $\begin{array}{l}\text { Force } \\
{[\mathrm{N}]}\end{array}$ & $\begin{array}{l}\text { Deflection } \\
{[\mathrm{mm}]}\end{array}$ & $\begin{array}{l}\text { MOR } \\
\text { [MPa] }\end{array}$ \\
\hline 950Al & 2592 & 0.51 & 194.4 & 3358 & 0.6 & 251.85 \\
\hline 1000Al & 2683 & 0.66 & 201.225 & 3368 & 0.69 & 252.6 \\
\hline 1050Al & 2900 & 0.53 & 217.5 & 5283 & 1.05 & 396.225 \\
\hline 1000Al Fe & 4963 & 1.00 & 372.225 & 5572 & 1.07 & 417.9 \\
\hline 1050Al Fe & 5314 & 0.60 & 398.55 & 7146 & 0.75 & 643.21 \\
\hline $\begin{array}{c}1050 \mathrm{Al} \\
\text { Boric acid }\end{array}$ & 6257 & 0.65 & 307.55 & 725.3 & 0.58 & 662.78 \\
\hline
\end{tabular}

